\title{
Desperate shadows of 'Belonging': Revealing pedagogical issues with teaching prescribed English texts in the NSW Higher School Certificate (HSC)
}

\author{
Melissa R. Jogie
}

Received: 14 August 2014/ Accepted: 24 November 2014

(C) The Australian Association for Research in Education, Inc. 2014

\begin{abstract}
As New South Wales (NSW) bids farewell to the 2009-2014 Area of Study concept 'Belonging', this article summarises some critical reflections from English teachers on the main pedagogical issues encountered when using prescribed texts to teach 'Belonging' to both the Standard and Advanced English courses in contemporary classrooms. These reflections are convened under three areas for further consideration, which includes an analysis of the Area of Study (NSW Board of Studies English Stage 6 Syllabus), an examination of the prescribed texts listed, and the main challenges teachers have identified with using both the NSW English Stage 6 Syllabus and set prescribed texts to engage contemporary students. The discussions raised in this article can be considered by NSW educators when selecting texts and designing units of work for teaching the new 2015-2020 Area of Study concept 'Discovery'.
\end{abstract}

Keywords Pedagogy - English texts - Culturally diverse texts - Area of Study · Belonging · Discovery · Higher School Certificate (HSC) · Board of Studies · Secondary education

\section{Introduction}

This article probes issues encountered by English teachers when mediating prescribed texts for the Area of Study in the NSW Higher School Certificate (HSC). To better understand the main pedagogical issues, concerning the planning and practices applied when teaching prescribed English texts (Carr 2002), there must firstly be an analysis of the NSW English Stage 6 Syllabus. The Area of Study

\footnotetext{
M. R. Jogie ( $\bowtie)$

College of Arts and Social Sciences, Centre for European Studies, Australian National University,

1 Liversidge Street, Building 67 C, Canberra, ACT 0200, Australia

e-mail: Melissa.jogie@anu.edu.au
} 
from the Board of Studies NSW English Stage 6 Syllabus has been selected for analysis as it the common content taught for both English Standard and Advanced courses. This shared content means the Area of Study is widely taught, for example in 2014 the majority of senior secondary students $(58,873$ out of a total of 75,472 students) in NSW sat either Standard or Advanced English courses (Board of Studies New South Wales 2014). Based on this fact an analysis, such as this, which identifies pedagogical issues encountered when teaching the aims of the Area of Study with prescribed texts, can be useful for educators who are considering how to better achieve the NSW English Stage 6 Syllabus aims when mediating set texts. The Area of Study aims (discussed further in this article) are broadly interpreted here, as encouraging students to critically read and extract meanings from texts, and subsequently apply their interpretations of these texts to reflect on their own culture and that of others. Based on this broad premise, this article investigates if the current range and quantity of prescribed texts are comprised of culturally diverse choices, which might better appeal to students from multicultural backgrounds.

Following a description of the Area of Study, this article turns to the range and quantity of prescribed texts that have been listed for studying the concept 'Belonging' for the past 6 years (2009-2014). Although 'Belonging' is the concept that is focused on in this article, there is also a presentation of the selected texts used to teach the previous concept 'Journey" (2004-2008), as well as new concept 'Discovery' (2015-2020). The prescribed texts listed for the Area of Study concepts from 2009-2020 are compared in order to analyse and identify patterns of frequency, range and quantity of texts listed for study over 11 years. This information is presented in order to establish how pedagogical challenges can emerge as a result of how often texts are repeated during these years, how often new texts are added to the reading list, and how the amount of texts for study is distributed through the varying text types. This discussion includes the rationale the NSW Board of Studies applies when selecting these texts above all others to be listed for the Area of Study in the NSW English Stage 6 Syllabus. It is important to note teachers are not required to teach all prescribed texts listed in the NSW English Stage 6 Syllabus. For clarity, this article only examines the prescribed texts for the Area of Study, in order to focus on the main pedagogical issues encountered when using these prescribed texts to teach the Area of Study for Standard and Advanced courses in the NSW English Stage 6 Syllabus.

The final section of this article focuses on discussing the main challenges educators encountered when teaching the Area of Study and using prescribed texts listed for the concept 'Belonging'. A total of twelve teachers from four different participating schools were questioned about what aspects of the Area of Study aims were often challenging to achieve when relating to the prescribed texts listed for 'Belonging'. It is important to note there were significantly different challenges for teaching the Area of Study in Standard and Advanced English courses, which perhaps filters back into questioning the general purpose of the Area of Study in the NSW English Stage 6 Syllabus. Teachers made recommendations on how these challenges can be better addressed by making changes to both the NSW English Stage 6 Syllabus and the list of prescribed texts. The following review presents existing research into English text selection practices both in Australia and overseas; 
this is important as it lays the foundation to further analyse pedagogical challenges and subsequent issues discussed in this article.

\section{Literature review}

Scholarly publications have argued that if there is a wide range of diverse texts students will be more inclined to engage in reading; as the learning goals of the Syllabus can be reinforced in meaningful ways regardless of their cultural background (Applebee 1994; Gambrell 1996; Hastie and Sharplin 2012; Ivey and Broaddus 2001; Lapp and Fisher 2009). However, recently published research in North American schools suggests that often well-known or canonical texts tend to remain on reading lists for decades, and continue to be taught with little consideration of the needs of contemporary learners, especially in multicultural classrooms (Johnston and Mangat 2012). Despite the fact that several studies (Athanases 1998; Brauer and Clark 2008; Davies et al. 2013; Ebe 2012; Friese et al. 2008; Goodwyn 2012; Hastie and Sharplin 2012; Holloway and Greig 2011; Lapp and Fisher 2009; Patterson 2012) have suggested that teaching a range of diverse texts to students from different cultural backgrounds is a highly effective method for supporting reading development, by building reading proficiency, as these texts better engage contemporary students in reading, interpreting and discussing issues of cultural differences as presented in texts.

In Australia, the Analysis of Literature in Australian Schools (ALIAS) project (Yiannakis 2014) identifies patterns of text selection from 1945 to 2005, which mapped reading lists for senior secondary education across Australia from the 1950s onwards. This research found that newer texts introduced between 1991 and 2005 were comprised of selections such as; 'Adventures of Huckleberry Finn', 'The Handmaid's Tale', 'Great Expectations', 'The Crucible' and 'Top Girls' to name a few, which were all listed as prescribed text options for the Area of Study between 2006 and 2014. According to the ALIAS these texts were not only popular across NSW but all of Australia (Yiannakis 2014). While existing research shows that there are a range of methods that can be applied to teach canonical texts so that they engage contemporary Australian readers (Davies et al. 2013), this does not necessarily mean that canonical texts should be removed from the NSW English Stage 6 Syllabus, nor does it mean these texts should continuously dominate prescribed reading lists. To identify patterns of text selection, this article presents the prescribed texts listed for three different Area of Study concepts over 11 years, in order to understand the frequency of repeating texts and the range and balance of well-known texts to more recently published options.

Particularly in the Australian context, this article aims to continue Patterson's argument that through English studies students can explore "weighty moral and ethical issues through the study of a broad range of texts and ... form judgements and develop tolerance as a result of their explorations [and this] is an important plank in the development of civil society", she argues though, “... there are signs however, that, especially at the senior levels of secondary schooling in Australia, this is not enough" (2008, p. 313). Perhaps a wider range of ethnically diverse texts 
will assist students from diverse cultural backgrounds to not only engage, but also challenge students to reposition themselves as readers that have to consider a wider range of contemporary issues beyond those presented in well-known or canonical texts (Athanases 1998). However, selecting a wide range of culturally diverse texts is not a simple task as there must be other considerations such as; what defines culturally relevant texts? How these texts appeal to different groups of students? Also how are these texts selected by teachers when considering the learning needs of their students?

In the United Kingdom Goodwyn's research heeds warning about autonomy and text selection in senior secondary schools by examining existing practices in a range of countries. Although his research is based on practices in England, he identifies that text selection in countries such as the United States, Canada, New Zealand and Australia have been recently considering how to balance the text selection process to have both representations of national identity with well-known or traditional (British/English) canonical texts. Goodwyn ascertains that "a significant difference in all four countries, compared with England, is the degree of classroom autonomy afforded to teachers and their freedom to choose texts and modes of assessment. It seems likely that these freedoms might be increasingly diminished, in that sense the story from England is a valuable 'warning' to English teachers around the world to protect the true importance of literature from political interference" (2012, p. 215). This suggests that text selection can become problematic if teachers are restricted to limited choices. In Australia, research into the selecting of Australian literature in senior English classrooms particularly in NSW showed that teachers stressed the importance of having autonomy when selecting texts for study, so that their units of work and subsequent lessons were better suited for their students (Patterson 2012). Although it can be argued that teachers can make choices from the list of prescribed texts, but research has shown that these choices are further influenced by a range of issues.

Research into how teachers select texts for their students has revealed that often the texts teachers select can affect student learning, as these texts encourage students to engage in certain kinds of knowledge. Therefore the process of selecting texts can lead to gaps in students' knowledge, which can result in selecting and repeating texts in order to meet the goals of assessment driven by both the Syllabus and final examinations (Friese et al. 2008). In Australia it seems most teachers base their selection of texts on preferences they might have for some texts rather than others. This is not entirely because teachers do not enjoy reading and exploring new texts, but text selection seems heavily influenced by the availability and accessibility of material that is well-resourced (Davies 2012). Texts are also selected based on what students have previously studied and what they are expected to study, as well teachers select some texts over others because they believe their students will engage and respond better to these texts as opposed to options.

\section{Methodology}

The following data has been extracted from the original findings of a doctoral thesis, examining how English texts are selected and taught to students from culturally 
diverse backgrounds in Australia and the United Kingdom. The data for this article is based on the Australian component of this research conducted in Sydney NSW. The following statements have been extracted from thirteen interviews conducted in NSW during March 2013. State schools and public selective schools were targeted for this research. Schools were targeted based on their academic performance rankings in the HSC English examinations, and this was a deliberate method of selection to better understand the range of pedagogical challenges that emerge for teachers who facilitate classes at both the top and lower end of Standard and Advanced English courses.

The field research methods of data collection include two sets of interviews; firstly an interview with a Senior English Syllabus Officer from the NSW Board of Studies was conducted to discuss the Board of Studies NSW English Stage 6 Syllabus, Area of Study and the process and rationale used for selecting prescribed texts. This was the administrative attempt to get a clearer understanding of NSW English Stage 6 Syllabus aims and how the overall process of selecting these texts above all others as prescribed texts help fulfil the requirements of the Area of Study in the NSW English Stage 6 Syllabus. The second sets of interviews were conducted with three English teachers at each of the four participating schools (see Table 1).

Once consent from the school to participate in this project had been attained, the Head of English at each school was invited to nominate teachers that he/she thought would be most suitable to contribute to this research. Teachers were interviewed separately, to better understand the challenges that exist with both the NSW English Stage 6 Syllabus and the list of prescribed texts for the Area of Study, and following the interview one of their English classes was observed. It was important to observe an English class being taught to get an understanding of the methods teachers used to discuss texts as well as map the backgrounds and attitudes of students in the classroom. For brevity purposes, this article only presents the data from the NSW Curriculum Officer and teacher interviews; in particular the questions related to the

Table 1 Description of Data for Schools and Teacher Interviews

\begin{tabular}{lllll}
\hline School & Type of School & Teacher & Sex & $\begin{array}{l}\text { Years of Teaching } \\
\text { Experience }\end{array}$ \\
\hline 1 & State school & 1 & Female & 20 \\
& & 2 & Female & 12 \\
& & 3 & Female & 10 \\
2 & 4 & Female & 30 \\
& Public selective school & 5 & Female & 5 \\
& & 6 & Female & 30 \\
3 & & 7 & Male & 6 \\
& & 8 & Female & 10 \\
& & 9 & Male & 10 \\
4 & & 10 & Female & 13 \\
& & 11 & Male & 8 \\
& & 12 & Male & 5 \\
\hline
\end{tabular}


Area of Study, the current range of prescribed texts and subsequent pedagogical challenges associated with mediating the NSW English Stage 6 Syllabus and prescribed texts to senior secondary students.

\section{Area of Study}

The Area of Study in the NSW English Stage 6 Syllabus aims to provide students with the opportunity to "explore, analyse and experiment with (i) meanings conveyed, shaped, interpreted and reflected in and through texts, (ii) ways texts are responded to and composed and (iii) connections between and among texts" (New South Wales Board of Studies 2012, p. 14). As mentioned the Area of Study is the common content between the Standard and Advanced English courses of study and comprises of $45 \mathrm{~h}$ of indicative study towards the HSC. The concept is central to the Area of Study as it guides the intention behind why and how students read and analyse prescribed texts. A concept based approach means the Area of Study guides students to, “... explore and examine relationships between language and text, and interrelationships among texts. [Students] examine closely the individual qualities of texts while considering the texts' relationships to the wider context of the Area of Study [concept]" (New South Wales Board of Studies 2012, p. 9). Therefore the prescribed texts should consist of a range of issues and examples that are relatable to the concept in the Area of Study.

This article focuses on the concept 'Belonging', which aims to investigate how, "perceptions and ideas of belonging, or of not belonging, vary. These perceptions are shaped within personal, cultural, historical and social contexts. A sense of belonging can emerge from the connections made with people, places, groups, communities and the larger world ... in terms of experiences and notions of identity, relationships, acceptance and understanding" (Board of Studies New South Wales 2013, p. 10). In the past Area of Study concepts have included: 'Changing' (2001-2003), 'Journeys' (2004-2008), 'Belonging' (2009-2014) and now 'Discovery' (2015-2020) (Board of Studies New South Wales 2013; New South Wales Board of Studies 2010). These concepts (past and present) share similarities by encouraging students to engage with the concept through the reading and analysis of prescribed texts in order to reflect on issues related to identity, relationships, acceptance and understanding. Therefore the range and variety of prescribed texts should be selected on the basis of the aims and requirements as listed in the NSW English Stage 6 Syllabus.

The Board of Studies NSW applies a framework for selecting texts for the Area of Study concepts, which is based on the criteria that assess texts by; (i) merit and cultural significance, (ii) needs and interests of students, and (iii) opportunities for challenging teaching and learning (Board of Studies New South Wales 2013). The prescribed texts are grouped into categories or textual types, meaning students taking Standard and Advanced English courses are required to study a fixed number of prescribed texts. For the Standard course, students must study one text from each of these four categories (i) prose fiction, (ii) drama, (iii) poetry and a (iv) non-fiction or film or media or multimedia text, whereas the Advanced course students study one text from each category, as well as a Shakespearean drama (Board of Studies New South Wales 2013). The prescribed texts put forward by the Board of Studies were defended as the best selection for teaching the 
Area of Study concept, since these texts were not only relevant and engaging for students to study, but were the most suitable texts to help students develop their understanding of culture and society by reading, analysing and interpreting concepts within texts (BOS NSW Senior Syllabus Officer Interview, Sydney, March 2013). However, this was not a view shared by many teachers who participated in this research.

The majority of teachers interviewed criticised the Area of Study as being an unnecessary module since it does not test any specific skills and "it's not intellectually stimulating," (School 3, Teacher 8 interview, Sydney, March 2013) for most students. The underlying criticism was that many students doing the Advanced English course were not challenged enough by the Area of Study concept and texts, and likewise many of the students doing the Standard course usually found it difficult to engage with the concept through studying the prescribed texts. For $83 \%$ of the teachers interviewed, the Area of Study had become repetitive to teach as, "the Board of Studies make us [teachers] do the same texts year after year and when they do change, it doesn't seem to change by very much" (School 2, Teacher 4 interview, Sydney, March 2013). Despite these general criticisms the Area of Study continues to maintain its function in the NSW English Stage 6 Syllabus for both Standard and Advanced English courses.

In response to the role or significance of the Area of Study in the NSW English Stage 6 Syllabus the NSW Board of Studies English Officer argued that the Syllabus aims are placed first and prescribed texts to accompany these aims are a secondary concern. While academics, like Michaels and Gold, might agree with the Board of Studies that, "texts are not an end in themselves ... texts are not what students learn about but they are the vehicles through which students learn about how meaning is made" (2006, p. 91), the Board of Studies maintained the argument that the current range of prescribed texts were engaging and suitable for contemporary students. Yet, the teachers interviewed for this research argued that in their classrooms this was not the case. A few teachers, who regarded the idea of concept-teaching as a useful approach, suggested that it would be more effective to teach the concept and texts if they were better selected to complement each other. Teacher 9 suggested to improve the Area of Study, “... maybe concepts need to be chosen more carefully ... there is a tendency to impose concepts on texts, rather than derive it from the text, when it's imposed on the text it's completely useless because it's false and it's artificial and it reads like that. And there is a labour-an absolute labour to be involved in it" (School 3, Teacher 9 interview, Sydney, March 2013). As teachers identified a gap between the Area of Study and the prescribed texts listed for studying the concept, the following presents some of these issues in more detail, to better understand what specific approaches or methods have been employed to diversify the current range of prescribed texts so that they addressed the Area of Study concept 'Belonging'.

\section{Prescribed texts}

An investigation into text selection patterns (illustrated in Table 2) shows that the concepts are not widely varied, and textual options listed to study 'Belonging' are easily interchanged and used to discuss other concepts like 'Changing', 'Journey' and 
now 'Discovery.' In addition to nominating interchangeable concepts, most of the prescribed texts listed have been repeated or reshuffled from other sections of the NSW English Stage 6 Syllabus, resulting in very few new texts being added to the prescribed list, when revised every 5 years. While it is not practical to expect that the Board of Studies will replace all prescribed texts on the NSW English Stage 6 Syllabus every 5 or now 6 years with new texts, as it would increase the costs of stocking the book room with new resources, despite being an option that would be seemingly advantageous for teachers and their students. Given this consideration, it can be asked how does changing the concepts but repeating the texts over an extended period of time, impact on how teachers present and engage students in studying texts?

According to teachers interviewed the overarching issue of mediating prescribed texts in senior secondary education seems to be that the Area of Study aims are partially achieved by teaching the prescribed texts. Teachers expressed that when planning and preparing to teach prescribed texts, they found the English texts themselves, as unrelated to the NSW English Stage 6 Syllabus, were generally good texts. However, when planning and preparing to teach the Area of Study concept in this instance 'Belonging', they identified there was a forced or unnatural method of manipulating or interpreting texts to fit the concept. One teacher elaborated on this issue, identifying that preparing to teach Year 12 (senior secondary) students, goes against all principles of being an effective English teacher (Anderson 1985). She explained,

English just isn't about—and I hope this isn't where it's heading-techniques and structure ... we need to get rid of the HSC. It has to go, it's so old! ... I get to the end of a ten week unit, knowing that all the amazing learning and discussion happening in your classroom will be reduced to a 1000 word essay, and to a certain point they can rote learn elements of it. This is because our rubrics are so parochial, and it's forcing the way we teach texts. Students are losing their creative thinking skills, they're losing their ability to take risks, they just want to be spoon-fed and they know that is exactly what the HSC is about. When I teach Year 12, I'm the teacher I never wanted to be, I'm a lecturer and a spoon-feeder. (School 2, Teacher 5 interview, Sydney, March 2013)

As explained above these texts are used to teach students, but the expectations of the NSW English Stage 6 Syllabus limits how texts are taught and furthermore how students learn and interpret these texts. Other teachers shared similar concerns that the current structure of the NSW English Stage 6 Syllabus - particularly the HSC does not encourage students to appreciate and engage with English texts. To elaborate further, Teacher 7 presents an argument that the NSW English Stage 6 Syllabus (particularly the Standard course) requires students to read prescribed texts and demonstrate a range of skills, including interpreting and applying meaning to their lives, yet students have to represent these interpretations through very strict guidelines in order to do well in the HSC. He argued that,

... you wonder why kids are bored of English? ... because we exhaust texts with concepts like 'Belonging.' Whatever the [Board of Studies] thought they 


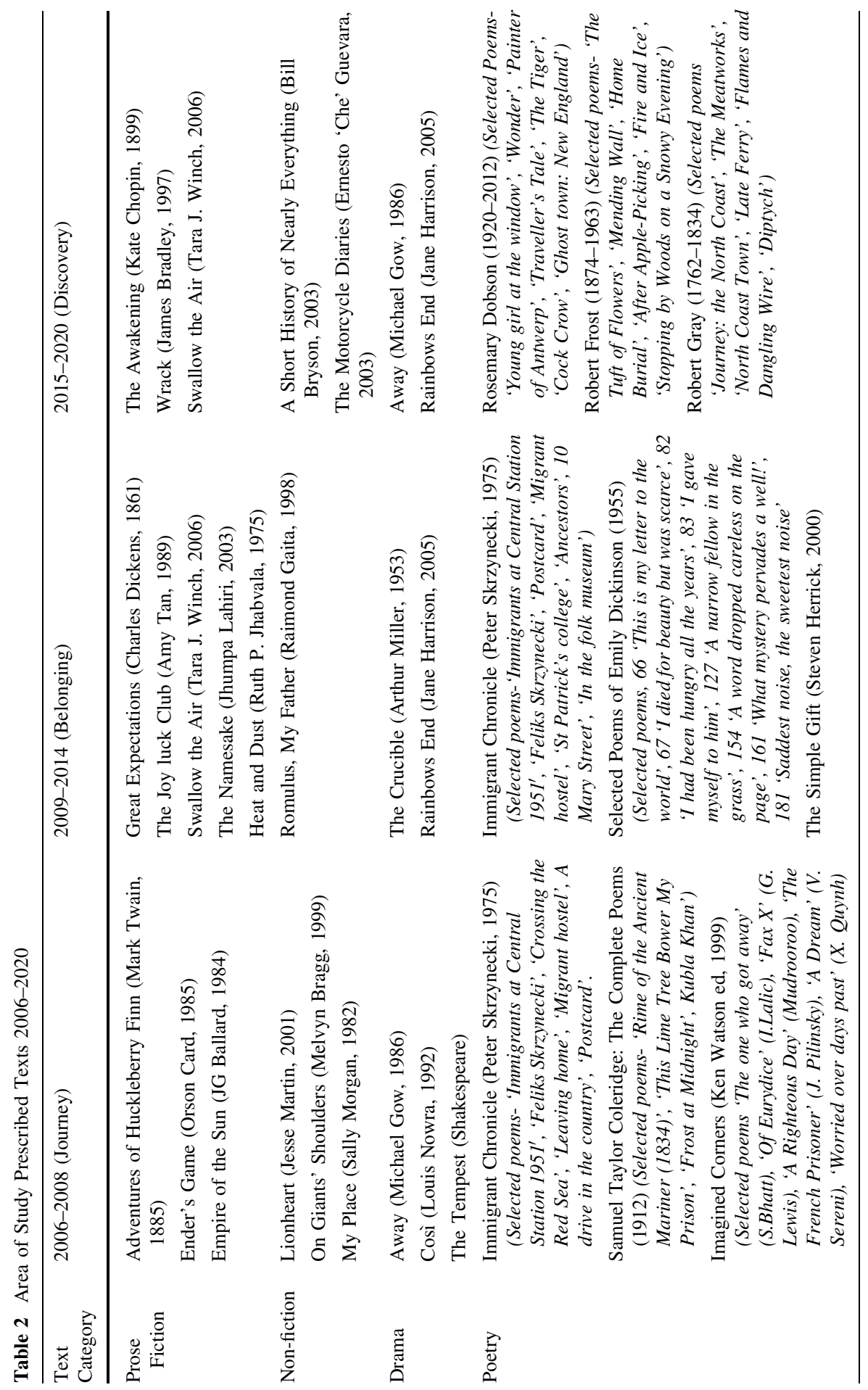




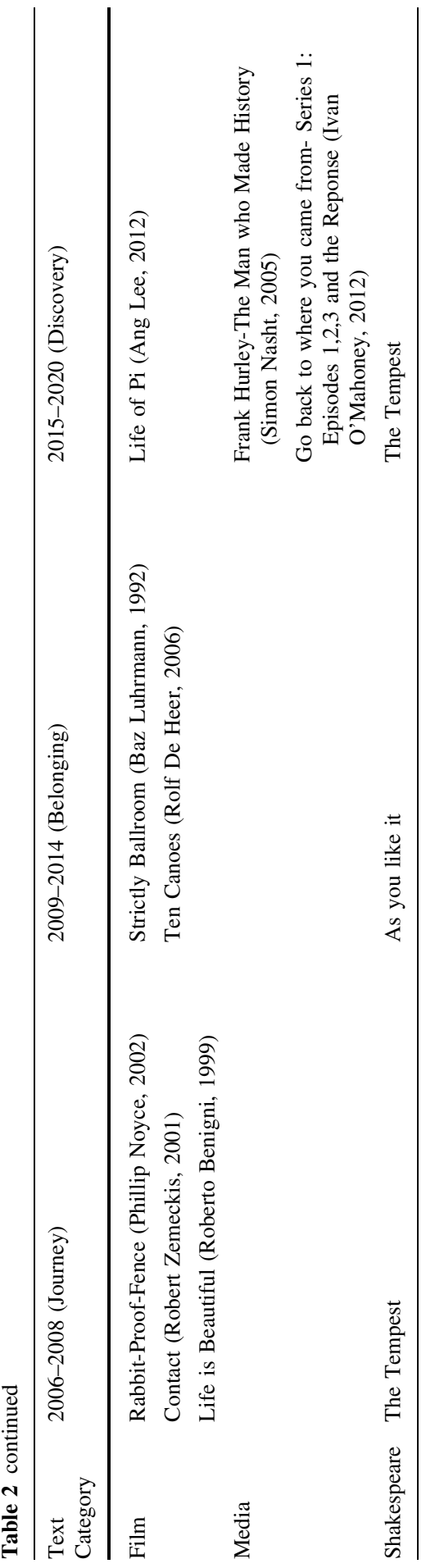


were doing when they set the Syllabus - that kids would go out and appreciate texts? ... and in fact it's the first thing [you read] on every rubric in the Prescriptions document for each text that, 'students will appreciate and enjoy ...', which is absolute bullshit! ... Students are only concerned about what they need to know to do well in their HSC, and if we [teachers] actually impart some meaning then that's a bonus. (School 3, Teacher 7 interview, Sydney, March 2013)

These bold statements seem to suggest that English teachers perhaps view the NSW English Stage 6 Syllabus content as a façade, because their teaching of texts to students is not to inspire them to seek meaning through these texts, but to regurgitate responses to texts that will help them do well in the HSC. This presents disengagement between the content specifications in the NSW English Stage 6 Syllabus and the pedagogical methods of relating these to prescribed texts. This research has found that most of the teachers interviewed have concerns about both the NSW English Stage 6 Syllabus and the prescribed texts, because the prescribed texts do not naturally meet the content specifications of this Syllabus.

The range of texts available on the prescribed text list (see Table 2) have been criticised by teachers, as not being modern, lacking diversity and are not frequently changed, which poses a challenge when encouraging students to engage with texts. Teacher 4 commented that, "the texts [are] primarily pretty old school literary canon types, with no emphasis on cultural diversity, considering the Australian population. I believe it would be nice if there was more of a balance with the canon, Australian Indigenous texts and other culturally diverse texts, but this would mean completely changing the HSC scaling and marking ... but [a balance of texts] would certainly equip the kids for life better" (School 2, Teacher 4 interview, Sydney, March 2013). This statement suggests a contemporary range of texts, including more culturally diverse options, might be seen as more beneficial to inform and engage students in discussions of cultural differences in society.

However, teachers argued that new, culturally diverse texts are difficult to include in the NSW English Stage 6 Syllabus. Teacher 9 suggested that the NSW system is context focus, not text focused, therefore texts are not seen as priority and because of this, "[the text list] does not change often enough, but there are practicalities involved, teachers have to read them and be able to teach them and you need skill and time to do that. You need training, resources, strategies, approaches" (School 3, Teacher 9 interview, Sydney, March 2013). Given this information, if the current list of texts is comprised of, "old school literary canon types" and new culturally diverse texts are difficult to incorporate into the NSW English Stage 6 Syllabus because teachers need, "training, resources, strategies [and] approaches" to teach these texts, then how is the current list of prescribed texts used in classrooms to engage contemporary and diverse learners?

Teachers commented that the current list of prescribed texts posed different challenges for groups of students depending on their learning abilities. For instance, teachers who were at schools, where the majority of students did Advanced English, made suggestions that advocated for texts to be removed on the basis that they were not challenging enough for these students, for example, "I would be tempted to take 
some of the easier texts off the Advanced course. I really don't see 'Romulus, My Father' as a text that would challenge Advanced students" (School 3, Teacher 9 interview, Sydney, March 2013). However, teachers with more classes of Standard English expressed opposite sentiments, saying that, “... sometimes it's really hard for our kids to engage with these texts and while we want to give them the opportunity to experience them, more focus on texts that are more culturally relevant to them might be more useful and help us reach them" (School 1, Teacher 1 interview, Sydney, March 2013). One teacher who reflected and compared her experience at different schools teaching both Advanced and Standard courses explained that using prescribed texts can make teaching quite a frustrating experience, because the prescribed texts currently listed do not easily satisfy the diversity requirements or varying levels of challenge that are needed to teach either Advanced or Standard classes. She commented that,

... the scope of books are very unimaginative. I don't think there is great text diversity out there. It seems the Board of Studies does not take notice of all the prize-winning literature that's coming out ... I think if I was teaching perhaps you know at a school with many culturally different backgrounds, that was less advantaged, and I was teaching Standard English, oh that would be woeful! You know I did teach a couple of years ago at a disadvantaged school but I have to say the texts did not inspire the students one bit. (School 2, Teacher 6 interview, Sydney, March 2013)

This statement suggests there is a significant gap between the learning requirements set out in the Advanced and Standard courses, where the prescribed texts for the Area of Study module do not entirely challenge or engage students taking either English course.

Another teacher suggested a reason the prescribed texts do not engage students in her Standard classes is because most of her students are from culturally diverse backgrounds and the prescribed texts are, “... very Anglo-centred, yeah they are! And there's like a smattering of text from other backgrounds but not a lot. There's still a fairly strong focus on what's considered to be important, White texts" (School 1, Teacher 3 interview, Sydney, March 2013). This opinion that texts are "Anglocentred or White texts," is perhaps the strongest argument for a wider range of culturally diverse texts to be included on the prescribed list, so that students doing the Standard course who "aren't very interested in English," (School 3, Teacher 8 interview, Sydney, March 2013), can become more involved in reading and learning about different cultures, as represented in texts and interpreted by others. A central issue that often emerges when teaching more traditional or canonical texts or "Anglo-centred, White texts", is that students doing the Standard course, who are perhaps less avid readers than those doing Advanced English, would find a text like Dickens' 'Great Expectations' a challenging read. This text would be a more challenging read because it speaks of a distant time, with norms and values far removed from those of a contemporary culturally diverse society.

Teachers have also commented that a major setback they encountered when teaching more traditional or canonical texts to contemporary students is that a majority of their teaching time is spent filling in the history around these texts. 
Teacher 9 remarked, “you can't assume that kids today [in Year 12 English] would have come across certain, let's say Christian iconography ... [for instance] when you've got a text that might allude to classic religious concepts-I don't know the fall- Adam and Eve, the Serpent, [or the] Garden of Eden-you look across the room and there's a sea blank faces, they don't know what you're talking about. So you have to do all of that" (School 3, Teacher 9 interview, Sydney, March 2013). However, for most traditional or canonical texts there is always a certain amount of history or background information that must be covered before reading the text itself and this constitutes the merit of having traditional or canonical texts on the NSW English Stage 6 Syllabus.

Most teachers agreed that more traditional, well-known texts are extremely important on the NSW English Stage 6 Syllabus, particularly for students doing Advanced or Extension courses. Teacher 11 summarised “... there is always a place for the traditional text. I just think depending on the group you're targeting, if you're looking at Advanced or Extension students, yeah you certainly need to have a focus on the traditional texts, but I think when it comes to the lower levels of English, like I teach the Standard groups, they don't even want to know Shakespeare" (School 4, Teacher 11 interview, Sydney, March 2013). When analysing the interviews for this research there was an apparent disparity (from the point of view of teachers) between the capabilities of Standard and Advanced students. Based on the feedback from teachers it seems that the prescribed texts might bore students doing Advanced English but significantly disadvantage those students doing the Standard course. The following unpacks the main issues teachers encountered when planning and preparing to teach prescribed texts in their classrooms. These issues help us understand the challenges and/or benefits associated with teaching the selection of prescribed texts to contemporary students.

\section{Challenges encountered when teaching prescribed texts}

One crucial finding identified in this research is the unnatural or forced connections teachers make between prescribed texts and the Area of Study concept. This is an important finding because it identifies how these prescribed texts are not read and taught in a manner to engage students to explore a range of interpretations and issues within texts, which is the ultimate aim of the Area of Study module. Teacher 5 explained how the concepts and the prescribed texts are not always compatible and this results in teachers narrowing how students engage and unpack reading and interpretations found in prescribed texts. She elaborated that,

... the disadvantage is that we fit texts that were never intended to be about belonging to [the concept] Belonging. For instance, Shakespeare's 'As you Like it', which we've been teaching for the last 6 years ... the links between this play and Belonging are so tenuous, we are really making superficial inroads here [and] there is really no deep learning occurring. If we see the word 'connection' or 'I love you' we go great that's about 'Belonging' to other people. So here we are studying Shakespeare who is meant to be really 
challenging and we study it at a superficial level because we're being forced to fit it with this concept of 'Belonging' that Shakespeare would have never intended 200 years ago. This kind of teaching narrows our focus, because there are such stronger concepts in 'As you Like it'. (School 2, Teacher 5 interview, Sydney, March 2013)

This statement raises additional questions, for instance to what extent are texts interpreted so that they better fit the content of the NSW English Stage 6 Syllabus and what are some of the subsequent effects or impacts on student learning? From this statement it appears that teaching texts in such a manner as to make 'superficial' connections to the Area of Study concept is prioritising the NSW English Stage 6 Syllabus aims over the actual reading and deep engagement associated with studying texts. If concepts and issues within prescribed texts are narrowed so they only focus on the NSW English Stage 6 Syllabus requirements (in this case to address 'Belonging'), this can restrict how students read texts, and ultimately their engagement with concepts beyond the learning goals. In other words, it seems for the Area of Study students will learn how to relate to ideas of 'Belonging' or not 'Belonging', and for this the NSW English Stage 6 Syllabus broadly includes a spectrum of perceptions to establish links of 'Belonging' within personal, cultural, historical and social contexts, however rather than having to pedagogically map all roads back to the concept of 'Belonging', students might be more open to read, interpret and engage with a range of different meanings found within these prescribed texts. Based on the arguments put forward in the above statement, a suggestion can be made that perhaps if concepts were redefined it would mean that the NSW English Stage 6 Syllabus aims and the current list of prescribed texts could be better taught to give depth to discussions in text while also satisfying the requirements of NSW English Stage 6 Syllabus.

Research has argued that concepts can be highly effective for teaching, but they must be linked to a sentence for example, "Prejudice is a destructive force in our society" (250) rather than just the open term 'prejudice' (Olson et al. 2010). For the 2009-2014 NSW English Stage 6 Syllabus examples of cultural differences encountered in prescribed texts were linked to the concept of 'Belonging'. However, as the Board of Studies puts forward concepts that are not specifically clarified or situated in a sentence, it becomes increasingly difficult to approach any given text and attempt to force all cultural concepts that are not necessarily or easily linked to issues of 'Belonging' or not 'Belonging' into the interpretation of a text. Due to time restrictions and preparations for the HSC, teachers commented that they have limited time to engage students in discussions beyond the learning goals of the NSW English Stage 6 Syllabus and in most cases students are not interested in discussing texts, beyond what is necessary to learn for their HSC exam. This suggests that in NSW the teaching and learning of English (for senior secondary students) is restricted by preparing for HSC examinations. In addition these limitations of how texts must be read to address the Area of Study concept for the HSC exams, teachers commented about yet another restriction they encounter by having limited options, in terms of the number of texts available to choose from each category. 
In the four participating schools the English teachers interviewed unanimously voiced concerns about the availability of only a few prescribed text options, and how this makes it difficult for them to plan units of work and select texts that are most suitable for their students. The NSW English Stage 6 Syllabus is structured so that one prescribed text from each category must be studied (refer to Table 2). This is summarised by Teacher 12 ,

... you have to choose so that each unit has a different text and there are only about two or three [texts] for each unit, so for 'Belonging' there is about two or three novels you can do, even one or two [texts] for some units. So when you've put in all of your preferences, there's always one unit where you say to yourself, 'I don't want to study this text, it doesn't suit my kids at all, it doesn't suit my preferred teaching style but I have to do it because if I don't do it in Module A, I'm going to have to change all of the texts that I teach' ... we need more texts for study so there is a variety for teachers to choose from. (School

4, Teacher 12 interview, Sydney, March 2013)

As illustrated in Table 2, there are a limited number of prescribed texts (total of 14) listed for study. This limited number has an impact on pedagogical methods of selecting and teaching these texts in senior English classrooms, where the priority for selecting texts to engage students, shifts from selecting texts that are most suitable or relevant for students, to strategically choosing texts that are perceived by teachers as less popular options for the HSC examinations. To further explain, Teacher 1 confirmed that limited text choices, particularly in cases where only one text is listed, for example only one prescribed text was offered for study can be seen in 2009-2014 ('Belonging' concept) where, 'Romulus, My Father' was the only text listed for non-fiction study. Similarly, there is another instance of this in the new 2015-2020 ('Discovery' concept), where 'Life of Pi' is the only text listed for film study (refer to Table 2). As a result of this teachers are, "forced to do texts that your kids might not do well [in], and that you don't like but you have to do it" (School 1, Teacher 3 interview, Sydney, March 2013). Such restrictions as limited text options mean that teachers are not always able to select texts that will be relevant for their students.

As a result of limited text options some teachers are motivated to select texts for alternative reasons, Teacher 1 explained, “... teachers make choices on some bizarre grounds, for instance 'there's not many kids doing this text, so I think there will be less competition for them getting higher marks', or 'I' $m$ at a selective school therefore I need to choose very academic texts for my kids to do' ... so priority lies mostly in these choices, not choosing texts that are interesting for their students" (School 1, Teacher 1 interview, Sydney, March 2013). It seems that although the NSW English Stage 6 Syllabus presents a broad concept for study ('Belonging'), the current range and number of prescribed texts limits how concepts can be studied. This situation is further compounded by the fact that teachers want their students to do well in the HSC exams, and therefore strategically select texts and (in most cases) repeat modules taught for several years, in order to help students focus on the specifics that will enable them to do well in the HSC. The above discussions suggest that perhaps if there was a wider range and number of prescribed texts available for 
the Area of Study, teachers might be more motivated to select texts that interest both them and their students.

In order to address the NSW English Stage 6 Syllabus aims using prescribed texts teachers seem to be narrowing their teaching strategies (as mentioned above) and as a result of this guiding their students to address only the issues found in prescribed texts that are relevant for their HSC examinations. For Advanced courses, students are more concerned about applying the information they learn in text to writing model essays for the HSC. Teacher 5 explained, “... our kids because they are gifted and talented they get to a point where they just freeze up and they don't want to take risks and don't want to play with creativity and innovation. They get scared about doing anything that isn't necessarily linked to a formula" (School 2, Teacher 5 interview, Sydney, March 2013). As a result this, students seem to limit their engagement with texts, and subsequently restrict how they apply their interpretations of these texts to their own or other cultures, which goes against the aims of the Area of Study in the NSW English Stage 6 Syllabus. In each participating school, teachers felt challenged by the notion that their role as educators dramatically changes when they teach senior secondary or Year 12 students who are preparing for their HSC examinations. One teacher added that formula teaching is becoming rampant in the education system and he claimed this is a direct result of examination testing. He suggested that, “...formula teaching is being encouraged perhaps not deliberately and perhaps not intentionally by our system in NSW, but the fact is it's an entire industry and it's being encouraged, there is now NAPLAN coaching as well ... it won't stop unless we change our style of assessment" (School 3, Teacher 9 interview, Sydney, March 2013). Given the nature of the HSC examination system, the broad NSW English Stage 6 Syllabus aims ('Belonging' in the Area of Study), and the limited prescribed text listed, teaching senior secondary English seems to have become more about securing passes than engaging students to read, reflect and learn about cultural differences in society, which is the principle aim of the Area of Study section of the NSW English Stage 6 Syllabus.

\section{Conclusion}

This article reviews the 2009-2014 Area of Study concept 'Belonging', with particular emphasis on issues encountered by NSW teachers when using prescribed texts to plan and prepare units of work for their classes of contemporary and culturally diverse students. Before discussing the pedagogical challenges it was firstly identified that most teachers expressed concern about the NSW English Stage 6 Syllabus aims, in regards to the Area of Study and listed prescribed texts, not adequately encouraging students to fulfil some of the shared learning goals intended for Standard and Advanced English courses. As a result of this apparent disconnect teachers felt they encountered pedagogical challenges with relating the Area of Study concept 'Belonging' to the prescribed texts, for instance teachers found that they were often forced to make unnatural connections between the concept and texts. In addition to this, the common texts listed for the Area of Study were either not challenging enough for students doing Advanced English, or overly challenging 
for those doing the Standard course. Based on the suggestions of the twelve English teachers interviewed for this research, either the NSW English Stage 6 Syllabus will need to change so that its aims and concepts are more broadly defined, or the scope and range of prescribed texts needs to be populated with more options so teachers can choose the most appropriate texts for their students. However, this research identified that text selection practices vary at different schools and a site for further investigation would be how English Departments at different schools prioritise these considerations when selecting texts for the school year, for instance are texts that would engage students given more precedence than texts available in the book room? To conclude, the last 5 years of 'Belonging' (2009-2014) might seem to finally be behind English teachers but, based on the evidence presented in this article, if these pedagogical issues go unaddressed it seems the road to 'Discovery' (2015-2020) might be filled with many desperate shadows of 'Belonging'.

\section{References}

Anderson, R. (1985). Notes to My Daughter, the New English Teacher. The English Journal, 74(3), 74-75. doi:10.2307/817116.

Applebee, A. N. (1994). Toward thoughtful curriculum: Fostering discipline-based conversation. The English Journal, 83(3), 45-52. doi:10.2307/820926.

Athanases, S. (1998). Diverse learners, diverse texts: Exploring identity and difference through literary encounters. Journal of Literacy Research, 30(2), 273-296. doi:10.1080/10862969809547999.

Board of Studies New South Wales. (2013). English Stage 6 Prescriptions: Area of Study, Electives and Texts Higher School Certificate 2015-20. Sydney: Board of Studies NSW.

Board of Studies New South Wales. (2014). 2014 HSC course enrolments. Educational Resource Board of Studies NSW. Accessed 26 October 2014 http://www.boardofstudies.nsw.edu.au/news-media/ media-guide-2014/stats/enrolments-course.html

Board of Studies New South Wales. NSW Syllabuses for the Australian curriculum. Students Learning English as an Additional Language or Dialect (EAL/D). Accessed 21 March 2014 http://syllabus. bos.nsw.edu.au/english/english-k10/eald/

Brauer, L., \& Clark, C. T. (2008). The trouble is English: Reframing English Studies in Secondary Schools. English Education, 40(4), 293-313.

Carr, D. (2002). Making sense of education: An introduction to the philosophy and theory of education and teaching: New York: Routledge.

Davies, L. M. (2012). Auditing subject English: A review of text selection practices inspired by the National Year of Reading. English in Australia, 47(2), 11-17.

Davies, L. M., Doecke, B., \& Mead, P. (2013). Reading the local and global: Teaching literature in secondary schools in Australia. Changing English, 20(3), 224.

Ebe, A. E. (2012). Supporting the Reading Development of Middle School English Language Learners Through Culturally Relevant Texts. Reading and Writing Quarterly, 28(2), 179.

Friese, E., Alvermann, D., Parkes, A., \& Rezak, A. (2008). Selecting texts for English Language Arts classrooms: When assessment is not enough. English Teaching: Practice and Critique, 7(3), 74.

Gambrell, L. B. (1996). Creating classroom cultures that foster reading motivation. The Reading Teacher, $50(1), 14-25$.

Goodwyn, A. (2012). The Status of Literature: English teaching and the condition of literature teaching in schools. English in Education, 46(3), 212-227. doi:10.1111/j.1754-8845.2012.01121.x.

Hastie, M., \& Sharplin, E. (2012). Why did you choose that text?: Influences on English teachers' choices of reading materials for students. English in Australia, 47(2), 36-44.

Holloway, S. M., \& Greig, C. J. (2011). Literacy text selections in secondary school classrooms: Exploring the practices of English teachers as agents of change. Brock Education, 20(2), 1.

Ivey, G., \& Broaddus, K. (2001). Just plain reading: A survey of what makes students want to read in middle school classrooms. Reading Research Quarterly, 36(4), 350-377. 
Johnston, I., \& Mangat, J. (2012). Reading practices, postcolonial literature, and cultural mediation in the classroom. Rotterdam: Sense Publishers.

Lapp, D., \& Fisher, D. (2009). It's all about the book: motivating teens to read. Journal of Adolescent and Adult Literacy, 52(7), 556-561.

Michaels, W., \& Gold, E. (2006). 'As time goes by’ or read it again, Sam. Metaphor, 1, 90-99.

New South Wales Board of Studies. (2010). Higher School Certificate Course Descriptions. Sydney

New South Wales Board of Studies. (2012). English : Stage 6 syllabus : English (standard), English (Advanced), English as a second language (ESL), English (Extension), Fundamentals of English/ Board of Studies, New South Wales: Sydney Board of Studies NSW

Olson, C. B., Land, R., Anselmi, T., \& AuBuchon, C. (2010). Teaching secondary english learners to understand, analyze, and write interpretive essays about theme. Journal of Adolescent and Adult Literacy, 54(4), 245-256. doi:10.2307/40961536.

Patterson, A. (2008). Teaching literature in Australia: Examining and reviewing Senior English. Changing English, 15(3), 311-322. doi:10.1080/13586840802364236.

Patterson, A. J. (2012). Australian literature: Culture, identity and English teaching. Journal of the Association for the Study of Australian Literature, 12(1), 1-17.

Yiannakis, J. (2014). A possible literary canon in upper school English literature in various Australian states, 1945-2005. Issues in Educational Research, 24(1), 98-113. 